\title{
KERAGAMAN DAN KEPADATAN POPULASI SPESIES BURUNG PADA KAWASAN HUTAN PENDIDIKAN UNIVERSITAS PAPUA
}

\section{(Diversity And Density Population Of Bird Species In The Area Of Educational Forest At University Of Papua)}

\author{
Carlie Mainase ${ }^{1}$, Hermanus Warmetan ${ }^{1 *}$ dan Anton Silas Sinery ${ }^{1}$ \\ Jurusan Kehutanan, Fakultas Kehutanan Universitas Papua Manokwari, Papua Barat, \\ 98314. Tlp/Fax: +62986211065.

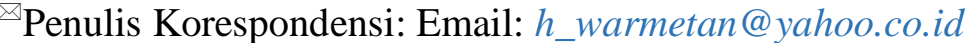 \\ Diterima: 03 Nov 2015| Disetujui: 17 Jan 2016
}

\begin{abstract}
Abstrak
Penelitian ini bertujuan untuk mengetahui keragaman dan kepadatan populasi burung pada hutan pendidikan dan kebun hortikultura Universiitas Papua. Metode point count (titik pengamatan) diaplikasikan dalam penelitian ini. Hasil penelitian menunjukkan bahwa nilai kergaman pada hutan tanaman adalah 1,88 hutan alam 2,63 dan kebun hortikultura adalah 1,68 sehingga keragaman burung pada ketiga lokasi tergolong dalam indeks kergaman sedang. Kepadatan populasi burung pada hutan tanaman adalah 4, 81 ekor/ha, hutan alam 15,5 ekor/ha dan kebun hortikultura adalah 11 ekor/ha. Hal ini menunjukkan bahwa perbedaan masing-masing spesies yang dikategorikan rendah, sehingga kelimpahan masing -masing jenis atau spesies tidak sama.
\end{abstract}

Kata kunci: Hutan pendidikan, jenis burung, kepadatan populasi, tipe habitat.

\begin{abstract}
Aim of this study was to acknowledge diversity and density population of bird species at Educational forest and horticultural farm belonged to University of Papua. Point count method was applied in this study. Result pointed out that the diversity value at plantation forest was 1.88, natural forest was 2.63, and horticultural land was 1.68. These bird variety values were in the moderate index for three different locations. Bird density population at plantation forest was $4.81 \mathrm{bird} / \mathrm{ha}$, natural forest was $15.5 \mathrm{bird} / \mathrm{ha}$, and 11 bird/ha was found at horticulture land. These indicated that there was a difference at each species which was categorically lower. Therefore, the abundance of each species was various.
\end{abstract}

Keyword: Bird species, density population, educational forest, habitat type.

\section{PENDAHULUAN}

Papua merupakan salah satu daerah di Indonesia bagian timur kepulauan Indonesia yang memiliki keanekaragaman spesies tumbuhan dan satwa yang tinggi. Keanekaragaman satwa ditunjukkan dengan ditemukannya sejumlah spesies di Papua yang antara lain meliputi kira-kira
164 spesies mamalia dan amfibi serta 650 spesies burung, sehingga dipastikan Papua memiliki setengah dari total keanekaragaman hayati di Indonesia (Conservation International, 1999).

Burung adalah salah satu kelompok fauna yang memiliki tingkat keragaman dan endemisitas tinggi di Papua. Beehler 
dkk (2001) menemukan lebih dari 700 spesies avifauna terdapat di Papua yang dibedakan menjadi empat kelompok yaitu 578 jenis berbiak di darat dan di air tawar, 40 jenis burung laut, 56 jenis burung migrant dari utara khatulistiwa dan 34 jenis migrasi dan pengembara dari Australia dan Selandia Baru. Jenis burung yang ada di Papua tersebut. 209 jenis diantaranya adalah endemik Papua karena memiliki keunikan tersendiri.

Burung merupakan salah satu komponen dari keanekaragaman hayati yang telah terbukti memberikan berbagai manfaat bagi kehidupan manusia. Manfaat tersebut dalam berbagai bentuk antara lain, dipelihara untuk dinikmati tingkah laku hidupnya. Alikodra (1990) menyatakan bahwa tingginya keanekaragaman jenis burung di suatu wilayah didukung oleh tingginya keanekaragaman habitat karena habitat bagi satwa liar secara umum berfungsi sebagai tempat untuk mencari makan, minum, istirahat, dan berkembang biak. Berdasarkan fungsi tersebut, maka keanekaragaman jenis burung juga berkaitan erat dengan keanekaragaman tipe habitat serta beragamnya fungsi dari setiap tipe habitat yang ada di hutan kota. Kelestarian burung dapat dipertahankan dengan melakukan konservasi jenis yang didahului dengan berbagai studi atau penelitian tentang satwa tersebut, antara lain mengenai keragaman, populasi, habitat dan lingkungan yang mempengaruhinya.

Habitat satwa liar terutama burung menempati kawasan hutan yang masih primer dimana kawasan hutan tersebut masih memiliki keanekaragaman vegetasi yang cukup beragam menjadi tempat yang baik bagi burung untuk mencari makan, beristirahat serta sebagai tempat berlindung yang merupakan faktor pendukung bagi habitat burung. Faktor perusak habitat yang utama adalah akibat aktivitas manusia. Hal ini dapat dilihat dengan adanya pembukaan lahan perladangan, penebangan kayu serta perburuan liar.

Hutan Pendidikan dan Kebun Hortikultura Universitas Papua (Unipa) merupakan salah satu hutan yang mempunyai berbagai jenis flora dan fauna, namun belum banyak yang diketahui fauna yang hidup didalamnya seperti jenis-jenis burung dan kepadatan populasi burung yang terdapat pada kawasan tersebut. Selain itu Hutan Pendidikan dan Kebun Percobaan Anggori merupakan salah satu hutan yang digunakan sebagai sarana praktek/penelitian yang terletak di Kabupaten Manokwari oleh pihak Universitas Papua, dengan luasan areal hutan alam mencapai 82 ha, hutan tanaman 10 ha dan kebun holtikultura seluas 31,2 ha yang didasarkan pada rencana pengelolaan tahun 2008. Kondisi potensi hutan anggori tersebut belum banyak diketahui terkait flora dan fauna yang ada di dalamnya. Dengan demikian hal ini menjadi pendorong dilakukan kegiatan penelitian yang dapat memberikan informasi ilmiah terkait status keberadan jenis-jenis fauna terutama burung di kawasan tersebut.

\section{METODE PENELITIAN}

Studi ini menggunakan metode point count (titik pengamatan) dengan cara melakukan monitoring per jalur dengan jarak antar jalur $100 \mathrm{~m}$. Sedangkan jarak dari titik ajir ke petak satu $50 \mathrm{~m}$, dengan jumlah petak sebanyak 30 petak baik di hutan tanaman, hutan alam dan areal perkebunan. 
Data primer yang dikumpulkan berupa kergaman jenis burung yang terdapat pada setiap jalur pengamatan, dan jumlah burung yang ditemukan pada setiap titik pengamatan serta vegetasi yang digunakan satwa sebagai habitat burung atau tempat pakan burung. Data sekunder merupakan data tambahan yang diperoleh melalui leteratur-literatur.

Pengumpulan keragaman jenis burung dilakukan dengan melihat gabungan antara jumlah jenis dalam dan jumlah inndividu masing-masing jenis dalam setiap petak atau titik pengamatan pada setiap jalur dengan systematic sampling berupa titik pengamatan point count. Jumlah titik pengamatan pada setiap lokasi berjumlah 30 titik, sehingga didapatkan 90 titik dengan jarak anatar jalur pengamatan 100 meter dan jarak antar petak 100 meter dengan radius 15 meter.

Kepadatan pupulasi ditentukan dengan systematic sampling berupa titik pengamatan (point count) dengan cara pengamat tetap berdiri dalam suatu lokasi/petak pada setiap jalur yang telah di buat dalam periode waktu 5 menit. Selanjutnya dicatat serta dihitung jenis burung yang terlihat maupun terdengar suaranya.

\section{HASIL DAN PEMBAHASAN}

\section{Komposisi Jenis}

Hasil pengamatan menunjukkan bahwa areal hutan pendidikan memiliki potensi burung khusunya burung diurnal yang cukup besar. Dari ketiga lokasi tersebut teridentifikasi 19 jenis burung dari 10 famili dimana 7 jenis ditemukan pada hutan tanaman yang didominasi oleh jenis Ptilinopus solomonensis, 17 jenis pada hutan alam dengan jenis dominan adalah Meliphaga sp., dan 9 jenis ditemukan pada kebun hortikultura yang didominasi oleh jenis Oedistoma pygmaeum flavipectus.

Dari jumlah burung diatas sebagaimana tercantum pada Tabel 1, bila dibandingkan dengan Safe (2011) yang mengidentifikasi 25 jenis dari 15 famili pada hutan pendidikan Anggori, maka jumlah jenis dan famili burung ditemukan pada penelitian lebih sedikit. Kondisi tersebut dipengaruhi adanya struktur dan komposisi jenis vegetasi penyusun areal, degradasi habitat akibat perusakan habitat dan adanya kegiatan perburuan yang dilakukan masyarakat sekitar terhadap satwa liar termasuk burung. Selain perusakan habitat dan kegiatan perburuan factor lain yang menyebabkan terjadinya penurunan jumlah jenis adalah kebisingan yang diakibatkan adanya kegiatan chain saw yang dilakukan masyarakat sekitar didalam areal hutan pendidikan, sehingga jumlah jenis yang ditemukan pun ikut menurun.

\section{Keragaman Jenis Burung}

Dari hasil pengamatan yang dilakukan yang meliputi hutan tanaman, hutan alam dan kebun hortikultura diidentifikasi 19 jenis burung dari 10 famili. Pada lokasi kebun hortikultura, terindikasi memiliki tingkatan yang berbeda-beda sesuai dengan aktivitas harian dan kebutuhan memperoleh makanan. Perbedaan keragaman jenis burung ini disebabkan oleh tingkat kesukaan makanan bagi burung seperti dikemukakan Odum (1994) bahwa keragaman spesies hewan termasuk burung dipengaruhi oleh tingkat ketersediaan makanan. Hasil perhitungan indeks keragaman jenis pada pada ketiga lokasi pengamatan jenis burung disajikan pada Gambar 1. 


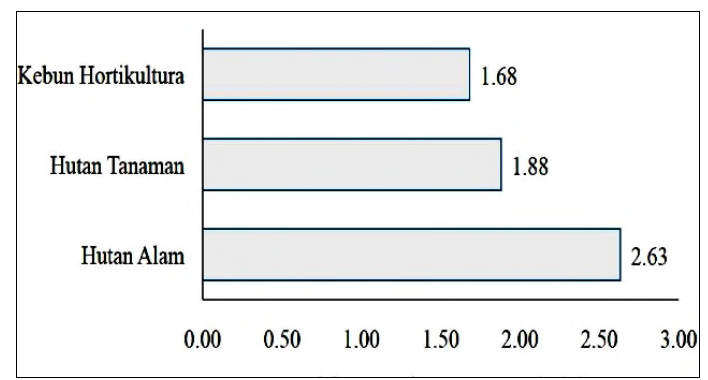

Gambar 1. Keragaman jenis burung pada ketiga lokasi pengamatan (hutan tanaman, hutan tanaman dan kebun hortikultura).

Berdasarakan nilai indeks keragaman jenis Shannon-Wiener pada Gambar 1, diketahui bahwa keanekaragaman jenis burung yang terdapat pada lokasi hutan alam adalah 2,63 yang tergolong dalam indeks keragaman sedang. Tingkat keanekaragaman jenis burung pada hutan tanaman dan kebun horkultura masing- masing sebesar 1,68 dan 1,88 yang juga masih tergolong dalam indeks keragaman sedang.

Kehadiran jenis-jenis burung pada setiap habitat memiliki tingkatan yang berbeda-beda sesuai dengan aktivitas harian dan kebutuhan memperoleh makan. Tiap habitat pada ketiga lokasi ini memiliki karakter yang berbeda sehingga ikut menentukan keragaman jenis burung yang terdapat didalamnya. Menurut Sinery dkk (2012) suatu komunitas dikatakan mempunyai keanekaragaman jenis yang tinggi jika komunitas tersebut disusun oleh banyak spesies dengan kelimpahan yang sama atau hampir sama. Sebaliknya jika komunitas itu disusun hanya oleh sedikit spesies dengan dominasi yang kecil maka keanekaragaman jenisnya rendah.

Tabel 1. Komposisi Jenis burung berdasarkan famili pada hutan pendidikan Unipa

\begin{tabular}{|c|c|c|c|}
\hline No. & Famili & Nama spesies & Nama lokal \\
\hline 1. & Acciptridae & $\begin{array}{l}\text { Henicopernis longicauda } \\
\text { Healistur Indus }\end{array}$ & $\begin{array}{l}\text { Elang ekor panjang } \\
\text { Elang bondol }\end{array}$ \\
\hline 2. & Alcenidae & Daceleo gaudichaud & Kakabura perut merah \\
\hline 3. & Bucerotidae & Ryctceros plicatus & Taon - taon \\
\hline 4. & Campephagidae & $\begin{array}{l}\text { Coracina malaena } \\
\text { Coracina sehistipceps }\end{array}$ & $\begin{array}{l}\text { Kepudang -sungu hitam } \\
\text { Kepudang-sungu desin }\end{array}$ \\
\hline 5. & Columbidae & $\begin{array}{l}\text { Calchops stephani } \\
\text { Ptillinopus solomonensis }\end{array}$ & $\begin{array}{l}\text { Delimukan timur } \\
\text { Walik salomon }\end{array}$ \\
\hline 6. & Corvidae & Corvus orru & Gagak orru \\
\hline 7. & Meliphagidae & $\begin{array}{l}\text { Pilemon buceredos } \\
\text { Meliphaga orientalis } \\
\text { Pynopygious ixoides } \\
\text { Melphaga Sp. }\end{array}$ & $\begin{array}{l}\text { Cikukua tanduk } \\
\text { Meliphaga gunung } \\
\text { Isap madu polos }\end{array}$ \\
\hline 8. & Nectariniidae & $\begin{array}{l}\text { Nectariniaa Jogularis } \\
\text { Naestarina Aspasia } \\
\text { Oedistoma pygmaeum flavipectus }\end{array}$ & $\begin{array}{l}\text { Burung-madu sriganti } \\
\text { Burung madu-hitam } \\
\text { Cucuk panjang }\end{array}$ \\
\hline 9. & Psittacidae & $\begin{array}{l}\text { Cactua galerita } \\
\text { Electus roratus }\end{array}$ & $\begin{array}{l}\text { Kakatua koki } \\
\text { Nuri bayan }\end{array}$ \\
\hline 10. & Sturnidae & Mino domontii & Mino-muka kuning \\
\hline
\end{tabular}


Namun, hasil pengamatan dan analisis indeks kesamaan (S) diketahui bahwa jumlah jenis yang ditemukan pada ketiga lokasi penelitian mempunyai keragaman jenis burung yang hampir sama. terlihat bahwa nilai indeks kesamaan untuk hutan alam dan hutan tanaman adalah 0,15 , dimana terdapat 7 jenis burung sama pada kedua habitat tersebut antara lain : Corvus orru, Nectarinia jogularis, Heliastus indus, Pilemonbuceroides, Henicopernis longicauda, Ryticerus plicatus dan Ptilinopus solomonensis. Sementara jenis yang hanya ditemukan pada hutan alam adalah Coracinasehistipceps, Naestarina asspasia, Meliphaga montana, Meliphaga orientalis,Meliphaga $\quad s p$., $\quad$ Cacatua galerita, Calchops stephani, Mino domontii, Dacaleogaudchaud dan Electus roratus.

Nilai indeks kesamaan jenis untuk hutan tanaman dan kebun hortikultura adalah 0,11 dimana terdapat 5 jenis burung sama antara lain : Corvos orru, Heliasturindus, Pilemon buceroides, Henicopernis longicauda, dan Ptilinopus solomonensis. Sementara yang hanya ditemukan pada kebun hortikultura adalah Oedistoma pygmaeum flavapectus dan Pyenopyious ixoides.

Nilai indeks kesamaan jenis untuk hutan alam dan kebun hortikultura adalah 0,09 dengan komposisi 7 jenis burung sama antara lain : Corvus orru, Heliastur indus, Pilemon buceroides, henicopernis longicauda, Cacatuagalerita, Electus roratus dan Ptilinopus solomonensis. Sementara jenis yang ditemukan pada hutan alam antara lain : Nectariniaa jogularis, Coracinasehistipceps, Naestarina aspasia, Meliphaga montana, Ryticerus plicatus, Meliphagaorientalis, Calchhops stephani, Mino domontii,
Dacaleo gaudichaud, dan Meliphagasp. Sedangakan jenis yang hanya ditemukan pada kebun hortikultura adalah Oedistoma pygmaeum flavapectus dan Pyenopyious ixoides.

\section{Kapadatan Populasi Burung}

Populasi burung pada hutan tanaman kecil dengan kepadatan populasi 4,81ekor/ha dimana Nectariniaa jogularis ditemukan 0,345 atau 1 ekor/ha, Heliastur indus 1 ekor/ha, Pilemon buceroides 1 ekor/ha, Ryticerus plicatus 1 ekor/ha dan Ptilinopussolomonensis 1,3 atau 2 ekor/ha dengan jenis dominan adalah Ptilinopus solomonensis. Sementara kepadatan populasi burung pada hutan alam adalah 15,56 ekor/ha dengan jenis yang mempunyaikerapatan yang tinggi adalah Meliphaga sp., (2,966 atau 3 ekor/ha) dan ikuti olehPtinilopus solomonensis.

Burung adalah spesies yang tingkat pergerakannya tinggi dengan jangkauan terbang yang jauhuntuk mencari makan, tetapi kadang - kadang memilki habitat bermain danberistirahat yang tersendiri. Kondisi ini menyebabkan bebrapa jenis tertentu jarangditemukan pada titik pengamatan.Sedangkan jumlah populasi pada kebun hortikultura adalah 11,17 ekor/ha dengan kerapatan tertinggi adalah Oedistoma pygmaeumflavapectus sebesar 4, 285 ekor/ha, diikuti oleh Pyenopyiouus ixoidesdengan kerapatan 3,196 ekor/ha. Jenis burung tersebut lebih banyak ditemukan padakebun hortikultura, karena terdapat jenis-jenis tanaman penghasilbuah yang menjadi sumber pakan.Dari kerapatan jenis burung pada ketiga lokasi habitat tersebut terlihat bahwa burung yang memilkikerapatan tertinggi adalah Ptinilopus solomonensis, Heliastur indus, Henicopernislongicauda, Pilemon buceroides, dan Corvos orru. 
Pebedaan aktivitas burung dibedakan menjadi dua sesuai dengan dilakukannya pengamatan pada pagi dan sore hari. Perbedaan aktivitas burung pada pagi hari dan sore hari yaitu pada pagi hari burungburung ditemukan mulai melakukan aktivitasnnya dengan terbang mencari makan dan bermain, sedangkan pada sore hari aktifitas yang mereka lakukan adalah terbang, bersuara mencari tempat yang aman untuk beristirahat.

Dari waktu beraktifitas dan aktifitas yang dilakukan burung yang terdapat pada hutan pendidikan khususnya hutan tanaman, burung-burung hanya menjadikan areal hutan tanaman sebagai tempat bermain dan tempat persinggahan untuk mencari makan. Hal ini disebabkan karena areal hutan tersebut berbatasan langsung dengan jalan sehingga burungburung tersebut jarang untuk ditemui.

\section{Habitat dan Vegetasi Kunci}

Tidak semua jenis vegetasi dijadikan sumber pakan, tempat bermain ataupun sebagai tempat tinggal. Burung mempunyai kemampuan untuk memilih habitat yang sesuai dengan kemampuannya untuk dijadikan tempat naungan dan habitat hidup. Terungkap bahwa jenis-jenis pohon dan vegetasi hutan yang sering dikunjungi burung antara lain: tegakan Ficus sp., liana liana, Pometia pinnata, Octomeles sumtrana, Stercullia,Zyzygium sp., Palaquium amboinensis, Callophylum inophyllum, Agathis labiliardieri dan Spatiostemon.

Pada umumnya habitat dapat mengalami perubahan kondisi musiman dan ketersediaan pakan. Kerusakan habitat atau perubahannya merupakan penyebab terjadinya perpindahan burung ke habitat yang lain. Hal ini dapat dilihat dengan adanya perbedaan jenis burung yang terdapat pada ketiga lokasi habitat. Kenyataan tersebut dapat diperkuat Odum (1994) bahwa perbedaan keragaman jenis burung disebabkan keterersediaan makanan bagi burung sehingga sangat mempengaruhi keragaman jenis burung. Namun, pembagian atau distribusi burung juga sangat di tentukan oleh kesesuaian habitatnya. Setiap jenis burung harus mampu beradaptasi dengan masingmasing tipe habitatnya, ketersediaan makan dan bertelur serta perilaku sosial atau kebiasaan harian. Selain itu dentuk tumbuh-tumbuhan merupakan bagian yang dominan dari habitat hutan yang dapat mempengaruhi keragaman jenis burung tetapi juga jenis satwa lain yang berda di dalamnya menjadi berkurang seperti saat ini yang terjadi pada hutan pendidikan dan kebun hortikultura Unipa.

\section{DAFTAR PUSTAKA}

Alikodra H.S. 1990. Pengelolaan satwa liar jilid I. Departemen Pendidikan dan Kebudayaan. Direktorat Jendral Pendidikan Tinggi Pusat Antar Universitas Ilmu Hayat IPB. Bogor.

Beehler, B.M.T.K. Pratt dan D.A. Zimmerman. 2001. Burung-burung di kawasan Papua, Papua New Guinea dan pulau-pulau satelitnya. Puslitbang Biologi. LIPI.

Conservation International. 1999. Report of Irian Jaya Biodiversity Conservation Priority Setting Workshop. Jakarta.

Demianus Safe. 2011. Keragaman dan kelimpahan jenis burung di hutan pendidikan Anggori Unipa pada hutan alam. Skripsi sarjana kehutanan (Tidak diterbitkan).

Odum E.P. 1994. Dasar-dasar ekologi. Edisi ketiga. Gadjah Mada University Press, Yogyakarta. 
Sinery A. Chandradewana Boer, Farida W.R. 2012. The Population condition and food availability of cuscus in Arfak Mountains Nature
Reserve, West Papua. Biodiversitas (Jurnal of Biological Diversity) 13(2):86- 